\title{
Renal vein thrombosis with recurrent pulmonary emboli in the nephrotic syndrome: use of the Greenfield filter
}

\author{
Anthony A. O'Brien, James P. O'Donnell and J.A. Brian Keogh \\ Department of Nephrology, Meath Hospital, Heytesbury St., Dublin 8, Republic of Ireland
}

\begin{abstract}
Summary: We describe a case of renal vein thrombosis in association with the nephrotic syndrome. The patient had recurrent pulmonary emboli which, having failed to respond to routine anticoagulant treatment, were managed successfully by the insertion of a Greenfield filter into the inferior vena cava above the renal vein thrombosis site. The only coagulation abnormality in this patient was a deficiency of antithrombin III.
\end{abstract}

\section{Introduction}

The reported incidence of renal vein thrombosis in association with the nephrotic syndrome ranges between $5 \%$ and $62.5 \%$ (Bennett, 1975; Pohl et al., 1977; Trew et al., 1978; Llach et al., 1980). It is now generally accepted that renal vein thrombosis is a complication of nephrotic syndrome rather than a causative factor in the pathogenesis of nephrotic syndrome (Llach et al., 1975; Chugh et al., 1981; Wagoner et al., 1983; Trew et al., 1978; Kauffmann et al., 1978). Recent studies have reported an $8.5-45 \%$ incidence of thrombotic complications other than renal vein thrombosis in patients with nephrotic syndrome (Kauffmann et al., 1978; Kanfer et al., 1970; Kendall et al., 1971). A hypercoagulable state is well described in renal vein thrombosis and nephrotic syndrome but the role of such a state in the pathogenesis of embolic complications has not been clearly proven (Kanfer et al., 1970.

Antithrombin III deficiency, previously described as contributing to this state of hypercoagulability (Kauffmann et al., 1978) was the only coagulation abnormality found in the patient reported here. Despite adequate anticoagulation with either heparin or streptokinase, the patient continued to suffer from life threatening recurrent pulmonary emboli. The patient's clinical state dramatically improved after the insertion and positioning suprarenally of a Greenfield filter. The use of a Greenfield filter in this clinical setting has not been previously described. Nine months after the insertion of the filter the patient is asymptomatic.

Correspondence: J.A. Brian Keogh, M.D., F.R.C.P.I. Accepted: 2 July 1985

\section{Case history}

A 40 year old male welder was admitted in August 1984 giving a one week history of bilateral leg oedema. Five weeks before this he complained of left loin pain. Investigations confirmed the diagnosis of nephrotic syndrome with a 24 hour urinary protein of $12.3 \mathrm{~g}$, a serum albumin of $18 \mathrm{~g} / \mathrm{l}$ and a serum cholesterol of $8.5 \mathrm{mmol} / 1$. There was no family history of a bleeding disorder. A subsequent renal biopsy showed a membranous glomerulopathy with margination of leucocytes. Full blood count, platelets and fibrinogen levels were normal: serum antithrombin III levels measured by immunodiffusion plating using a known concentration of antithrombin III as control was $0.15 \mathrm{~g} / 1$ (normal $0.2-0.4 \mathrm{~g} / \mathrm{l}$ ). There was no clinical evidence of malignancy.

On day 9 of the admission the patient complained of left pleuritic chest pain. Chest X-ray and a ventilation/ perfusion scan confirmed the presence of pulmonary emboli and intravenous heparin was commenced. We experienced difficulty with heparinization 120,000 IU being needed to achieve adequate partial thromboplastin time (Kaolin) prolongation.

On day 12 the patient deteriorated with increasing respiratory distress and clinical shock. A streptokinase infusion was begun using $600,000 \mathrm{IU}$ as a bolus and 100,000 IU hourly intravenously for 36 hours, with dramatic improvement.

On day 15 the streptokinase infusion was discontinued and heparin recommenced. The antithrombin III level at this stage was $0.15 \mathrm{~g} / \mathrm{l}$ and was also detected in the patient's urine. We again experienced difficulty 
with heparinization despite an infusion of fresh frozen plasma at a rate of $15 \mathrm{ml} / \mathrm{kg}$.

On day 19 clinical deterioration with increasing respiratory distress reoccurred. Streptokinase was recommenced. An inferior venocavogram with selective renal venography revealed a semi-occlusive thrombus in the right renal vein. A Greenfield filter was inserted via the internal jugular vein to rest above the right renal vein in the inferior vena cava.

The patient's clinical condition gradually improved with no further recurrence of pulmonary emboli. Nine months after the insertion of the Greenfield filter the patient is asymptomatic, the antithrombin III levels are normal, and the nephrotic syndrome is now in remission.

\section{Discussion}

The incidence of renal vein thrombosis secondary to nephrotic syndrome has been increasing recently. This undoubtedly reflects the more widespread use of selective renal venography in patients with nephrotic syndrome. Formerly the clinical findings of flank pain, haematuria and deterioration of renal function were thought to be essential for making the diagnosis of renal vein thrombosis (Hasson et al., 1957). However, more recent larger series have described these findings in less than $30 \%$ of cases of renal vein thrombosis (Llach et al., 1975; Chugh et al., 1981; Wagoner et al., 1983). Furthermore the notching of ureters on intravenous urography, classically associated with renal vein thrombosis, is seen in less than $25 \%$ of cases (Llach et al., 1975; Chugh et al., 1981; Wagoner et al., 1983). These findings form the basis of the acute and chronic renal vein thrombosis classification as devised by Llach et al. (1980). Hence the true incidence of renal vein thrombosis in nephrotic syndrome is probably still underestimated.

Many coagulation factor abnormalities have been described in patients with nephrotic syndrome. These include elevated platelet and fibrinogen levels together with increased activity of Factors V, VII, VIII and X (Kanfer et al., 1970; Kendall et al., 1971; Thomson et al., 1974). Antithrombin III deficiency in a patient with nephrotic syndrome and renal vein thrombosis was first described by Kauffmann et al. (1976) and further elucidated by him in a study of 48 patients with nephrotic syndrome (Kauffmann et al., 1978). However Kanfer et al. (1970) have shown that the concentration of other antithrombins (e.g. alpha II macroglobulin) may rise and that the total antithrom- bin activity, even allowing for the antithrombin III deficiency, is normal. Consequently, without having measured the concentration of alpha II macroglobulin, we cannot definitely attribute the pathogenesis of the recurrent pulmonary emboli to antithrombin III deficiency alone. It is also difficult to correlate these findings of a hypercoagulability state with clinical experience in that many patients with nephrotic syndrome and a hypercoagulable state do not have renal vein thrombosis or thromboemboli.

We are in no doubt that the insertion of the Greenfield filter saved this patient's life. The insertion of transvenous filters via a venous cutdown was first used in critically ill patients with either a contraindication to or a complication of routine anticoagulation with heparin or warfarin (De Weese \& Hunter, 1963; Mobin-Uddin et al., 1969; Greenfield et al., 1973). This indication for their insertion has gradually been superceded by recurrent emboli not responding to anticoagulants (Greenfield et al., 1981). The long term patency of the Greenfield filter is estimated at $95 \%$ and the incidence of recurrent pulmonary emboli after the insertion of the filter is $2 \%$ (Greenfield et al., 1981). A suprarenal position for the filter is unusual (present in $7 \%$ of cases reported by Greenfield et al., 1981) and to our knowledge this is the first time it has been used in a patient with nephrotic syndrome, renal vein thrombosis and recurrent pulmonary emboli. A recent innovation has been the introduction of a pre-loaded less bulky filter which, by obviating the need for venous cutdown, allows for quicker insertion which could prove beneficial in a life threatening situation (Roehm et al., 1984).

We would suggest that, in the nephrotic syndrome where clinical pulmonary emboli exist, renal vein thrombosis is the likely source. Pulmonary emboli are an important clue to renal vein thrombosis $2 / 3$ of which are clinically silent (Llach et al., 1975; Chugh $e t$ al., 1981; Wagoner et al., 1983). We also suggest that, in nephrotic syndrome with pulmonary emboli where difficulty with heparinization or anticoagulation is encountered and the patient is critically ill, a Greenfield filter be inserted.

\section{Acknowledgements}

We would like to thank Professor D. Bouchier-Hayes of the Richmond Hospital, Dublin 7 who inserted the Greenfield filter. We would also like to thank Miss Rosaleen Barber and Miss Avril Poff for their help in preparing the manuscript. 
References

BENNETT, W.M. (1975). Renal vein thrombosis in nephrotic syndrome. (Letter). Annals of Internal Medicine, 83, 577.

CHUGH, K.S., MALIK, N., UBEROI, H.S., GUPTA, V.K., AGGARWAL, M.L., SIGNHAL, P.C., SURI, S. \& JAIN, S.K. (1981). Renal vein thrombosis in nephrotic syndrome - a prospective study and review. Postgraduate Medical Journal, 57, 566.

DE WEESE, M.S. \& HUNTER, D.C., Jr. (1963). A vena cava filter for the prevention of pulmonary embolism: a five year clinical experience. Archives of Surgery, 86, 852.

GREENFIELD, L.J., MCCURDY, J.R., BROWN, P.P. \& ELKINS, R.C. (1973). A new intracaval filter permitting continued flow and resolution of emboli. Srugery, 73, 599.

GREENFIELD, L.J., PEYTON, R., CRUTE, S. \& BARNES, R. (1981). Greenfield vena caval filter experience. Results in 156 patients. Archives of Surgery, 116, 1451.

HASSON, J., BERKMAN, J.I. \& RIFKIN, H. (1957). A clinicopathological study of chronic renal vein thrombosis in adults. Annals of Internal Medicine, 46, 493.

KANFER, A., KLEINKNECHT, D., BROYER, M. \& JOSSO, F. (1970). Coagulation studies in 45 cases of nephrotic syndrome without uraemia. Thrombosis and Haemostasis., $24,562$.

KAUFFMANN, R.H., DE GRAEFF, J., BRUTEL DE LA RIVIERE, G. \& VAN ES, L.A. (1976). Unilateral renal vein thrombosis and nephrotic syndrome. American Journal of Medicine, 60, 1048.

KAUFFMANN, R.H., VELTKAMP, J.J., VAN TILBURY, N.H.\& VAN ES, L.A. (1978). Acquired antithrombin III deficiency and thrombosis in the nephrotic syndrome. American Journal of Medicine, 65, 607.
KENDALL, A.G., LOHMANN, R.C. \& DOSSETOR, J.B. (1971). Nephrotic syndrome. A hypercoagulable state. Archives of Internal Medicine, 127, 1021.

LLACH, F., ARIEFF, A.I. \& MASSRY, S.G. (1975). Renal vein thrombosis and nephrotic syndrome. Annals of Internal Medicine, 33, 8.

LLACH, F., PAPPER, S. \& MASSRY, S.G. (1980). The clinical spectrum of renal vein thrombosis: acute and chronic. American Journal of Medicine, 69(6), 819.

MOBIN-UDDIN, K., MCCLEAN, R. \& JUDE, J.R. (1969). A new catheter technique of interruption of inferior vena cava for prevention of pulmonary embolism. American Surgery, 35, 889.

POHL, M.A., McLAURIN, J.P. \& ALFIDI, R.J. (1977). Renal vein thrombosis and the nephrotic syndrome. Abstracts of 10th Annual Meeting of American Society of Nephrology, Washington D.C., 10, 20A.

ROEHM, J.O.F., GIANTURCO, C., BARTH, M.H. \& WRIGHT, K.C. (1984). Percutaneous transcatheter filter for the inferior vena cava. Radiology, 150, 255.

THOMSON, C., FORBES, C.D., PRENTICE, C.R.C. \& KENNEDY, A.C. (1974). Changes in blood coagulation and fibrinolysis in the nephrotic syndrome. Quarterly Journal of Medicine, 43, 399.

TREW, P.A., BIAVA, C.G., JACOBS, R.P. \& HOPPER, J. (1978). Renal vein thrombosis in membranous glomerulonephropathy: incidence and association. Medicine, 57, 69.

WAGONER, R.D., STANSON, S.W., HOLLEY, K.E. \& WINTER, C.S. (1983). Renal vein thrombosis in idiopathic membranous glomerularopathy and nephrotic syndrome: incidence and significance. Kidney International, 23, 368. 